\title{
Synthesis, characterization and catalytic performance of a novel zeolite ITQ-2-like by treating MCM-22 precursor with $\mathrm{H}_{2} \mathrm{O}_{2}$
}

\author{
LING XU ${ }^{1,2}$, HAIJUN XING ${ }^{1}$, SHUJIE WU ${ }^{1}$, JINGQI GUAN ${ }^{1}$, MING JUN JIA ${ }^{1}$ and \\ QIUBIN KAN ${ }^{1, *}$ \\ ${ }^{1}$ College of Chemistry, Jilin University, Changchun 130023, P.R. China \\ ${ }^{2}$ College of Chemistry and Chemical Engineering, Inner Mongolia University for Nationalities, \\ Tongliao 028000, P.R. China
}

MS received 22 November 2009; revised 11 January 2010

\begin{abstract}
A novel zeolite material denoted as ITQ-2-like was synthesized by treating MCM-22 precursor with $\mathrm{H}_{2} \mathrm{O}_{2}$ and characterized by various physicochemical techniques (X-ray powder diffraction, transmission electron microscopy, thermogravimetric-differential thermal analyses, Fourier transform infrared spectroscopy and nitrogen adsorption-desorption). It was found that not only the organic template could be completely removed but also the morphology and topology structure of MCM-22 precursor was well preserved after $\mathrm{H}_{2} \mathrm{O}_{2}$ treatment. Novel zeolite material ITQ-2-like presented relatively ordered cascaded layers in a faceto-face orientation along the $c$-axis and exhibited different physicochemical properties in comparison with ITQ-2 and MCM-22 prepared from the same precursor. Moreover, the catalytic behaviour and pore roles of three kinds of Mo-containing catalysts of ITQ-2-like, MCM-22 and ITQ-2 were investigated in the reaction of methane aromatization.
\end{abstract}

Keywords. ITQ-2-like; MCM-22; ITQ-2; $\mathrm{H}_{2} \mathrm{O}_{2}$ treatment; methane aromatization.

\section{Introduction}

MWW-type zeolites, such as MCM-22 (Corma et al 2000a), MCM-49 (Daria et al 1996), MCM-36 (Barth et al 2004) and MCM-56 (Juttu and Lobo 2000), exhibited unusual catalytic properties in several chemical reactions, for example in aromatization (Ma et al 2001; Wang et al 2004), alkylation (Rigoreau et al 2005; Laforge et al 2005) and gas-oil cracking (Corma et al 1999). It was found that the change of morphology of these MWW-type zeolites could influence the acidity and catalytic properties (Corma et al 2000b; Wu et al 2005). Therefore, some research work was focused on developing new materials with MWW structure by using different synthesis and/or post-treatment methods (Corma et al 1998). It was well known that MCM-22 precursor, viz. assynthesized MCM-22, was made up of silicate layers. Upon calcination, condensation of the layers of MCM-22 precursor occurred accompanied by the removal of the organic template, thus creating an independent surpercage system to form MCM-22 zeolites (Leonowicz et al 1994). The layers of MCM-22 precursor could also be swollen with suitable swelling agents. The resultant swollen material was submitted to ultrasound treatments and then

\footnotetext{
*Author for correspondence

(guangjq@jlu.edu.cn; gkan@mail.jl.edu.cn)
}

followed by calcination to produce zeolite ITQ-2. In addition, the swollen material could also be pillared in a face-to-face orientation to prepare MCM-36 bearing the characteristic of microporosity and mesoporosity. Notably, the original MWW structure or morphology has been changed during the post-treatment or calcination process.

Recently, it is reported that the detemplation of zeolite beta could be achieved by oxidation of the template using $\mathrm{H}_{2} \mathrm{O}_{2}$ (Melián-Cabrera et al 2005). With this approach, the original structure of the material was well preserved and no extra-framework aluminum was formed. In our recent work, the detemplation of MCM-56 using $\mathrm{H}_{2} \mathrm{O}_{2}$ was successfully carried out, and this treatment could avoid destroying pristine MWW structure (Xing et al 2008). Here, we report a novel zeolite material (ITQ-2like) with MWW structure by treatment of MCM-22 precursor with $\mathrm{H}_{2} \mathrm{O}_{2}$. The results show that the organic template could be completely removed by this method. Moreover, the pristine MWW structure and morphology of MCM-22 precursor were found to be well preserved.

To our knowledge, the family of MCM-22 has exhibited potential in many catalytic reactions. Especially, Mo supported on MCM-22 or MCM-49 zeolites have exhibited greater catalytic activity compared to other catalysts in the direct conversion of alkanes into aromatics. It has been proposed that the structures of zeolites can considerably influence the catalytic property of methane aromatization (Chen et al 1995; Xu et al 1995; Wang et al 
1997; Borry et al 1999; Ding et al 2002). Previously, we considered that the presence of supercage and 10-ring channels played a positive role to produce benzene (Xing et al 2008). Furthermore, the presence of large amounts of 12-ring cups exposed to the crystal exterior was beneficial for increasing the amount of coke. In this work, the physicochemical and catalytic properties of ITQ-2-like as support were studied in methane non-oxidative aromatization reactions in comparison with MCM-22 and ITQ-2. The roles of the MCM-n structure would be further investigated in methane aromatization.

\section{Experimental}

\subsection{Synthesis of ITQ-2-like}

According to the literature (Wu et al 2005), MCM-22 precursor with $\mathrm{Si} / \mathrm{Al}=25$ was synthesized by using hexamethyleneimine (HMI) as the template and silica gel as the silica source. The original slurry was obtained by stirring the mixture containing certain amounts of sodium aluminate, silical gel, HMI and water for $30 \mathrm{~min}$. To shorten crystallization time, MCM-22 powder was added as the seed. The resulting slurry was placed in $50 \mathrm{ml}$ of PTFE-lined stainless steel autoclaves. After being crystallized at $443 \mathrm{~K}$ for $2 \mathrm{~d}$, the resulting solid was filtrated, washed and dried to receive MCM-22 precursor.

Under continuous stirring, the MCM-22 precursor was treated with 30 wt. $\% \mathrm{H}_{2} \mathrm{O}_{2}$ solution (liquid-to-solid ratio of $10 \mathrm{~cm}^{3} / \mathrm{g}$ ) in a flask at $363 \mathrm{~K}$ for $1 \mathrm{~d}$, and then filtered and dried at ambient conditions. The novel zeolite ITQ-2like was obtained by this method.

As reference samples, MCM-22 and ITQ-2 were also prepared. MCM-22 was obtained by calcining a part of MCM-22 precursor in a muffle at $773 \mathrm{~K}$ for $5 \mathrm{~h}$. And the ITQ-2 was prepared by the delamination of a certain amount of MCM-22 precursor. The detailed process of the swelling and ultrasound for MCM-22 precursor was followed as previously reported in the literature (Corma et al 1998).

\subsection{Preparation of $\mathrm{Mo} / \mathrm{H}-\mathrm{ITQ}$-2-like zeolite,} Mo/H-MCM-22 and Mo/H-ITQ-2

It was well known that both acidity of zeolite support and active molybdenum species loaded on the zeolite support should be responsible for the catalytic behaviour in methane non-oxidative aromatization. Hence, the protonated forms of ITQ-2-like, MCM-22 and ITQ-2 together with loaded molybdenum catalysts were needed in this work. Firstly, the ammonium forms of ITQ-2-like, MCM22 and ITQ-2 were prepared by ion exchange in $2 \mathrm{~mol} / \mathrm{l}$ aqueous solutions of ammonium nitrate $\left(10 \mathrm{~cm}^{3} / \mathrm{g}\right)$ at $358 \mathrm{~K}$ for $3 \mathrm{~h}$. Molybdenum-loaded zeolite catalysts were prepared through impregnation method. $\left(\mathrm{NH}_{4}\right)_{6} \mathrm{Mo}_{7} \mathrm{O}_{24}$.
$4 \mathrm{H}_{2} \mathrm{O}$ with a Mo content of 6 wt. $\%$ was dissolved in $3 \mathrm{ml}$ $\mathrm{H}_{2} \mathrm{O}$ and mixed with $\mathrm{NH}_{4}-\mathrm{MCM}-22, \mathrm{NH}_{4}$-ITQ-2-like and $\mathrm{NH}_{4}$-ITQ-2. After evaporating water at $353 \mathrm{~K}$, the solid samples were calcined in air at $773 \mathrm{~K}$ for $5 \mathrm{~h}$. The three catalysts were designated as Mo/H-MCM-22, Mo/H-ITQ2-like and Mo/H-ITQ-2.

\subsection{Characterization of samples}

X-ray powder diffraction (XRD) measurements were carried out using $\mathrm{CuK} \alpha$ radiation on a SHIMADZU XRD6000 diffractometer in the range of $5-40^{\circ}(2 \theta)$.

The morphology of the zeolites was observed by a HITACHI H-8100 electron microscope operating at an accelerating voltage of $200 \mathrm{kV}$.

Fourier transform infrared (FT-IR) spectra of skeletal vibration of the zeolites were recorded using $\mathrm{KBr}$ flake on a Shimadzu Nicolet Avatar 370 DTGS spectrometer.

Thermogravimetric-differential thermal analyses (TGDTA) were run from 300 to $900 \mathrm{~K}$ at a rate of $20 \mathrm{~K} / \mathrm{min}$ under a flow of air using a DTG-60.

The specific surface area and pore volume from nitrogen adsorption isotherms were determined using Micromeretics, ASAP 2020 apparatus after the samples were pretreated under vacuum at $623 \mathrm{~K}$ overnight. Microporous surface area and pore volume were estimated by $t$-plots, and mesoporous surface area and volume were determined by BJH method between 2 and $50 \mathrm{~nm}$ (Harkins and Jura 1943).

The acidity of zeolites was determined after the adsorption of $d_{3}$-acetonitrile by IR spectroscopy using a Shimadzu Nicolet Avatar 370 DTGS spectrometer (Wichterlová et al 1998; Čejka et al 2002). Zeolite samples were pressed in the form of self-supported wafers, fixed in a quartz holder and then introduced into an infrared cell with $\mathrm{CaF}_{2}$ windows. Before adsorption of $d_{3}$-acetonitrile, the zeolites were treated in situ by evacuation at $473 \mathrm{~K}$ in $10^{-5} \mathrm{mmHg}$. Adsorption was carried out at $298 \mathrm{~K}$ for $15 \mathrm{~min}$, followed by an evacuation for $30 \mathrm{~min}$ at the same temperature. Then the measured spectra were normalized to a wafer thickness of $1 \mathrm{mg} / \mathrm{cm}^{2}$.

\subsection{Catalytic test}

Catalytic tests were carried out under atmospheric pressure in a continuous flow fixed-bed quartz reactor of $1 \mathrm{~cm}$ ID, which was charged with $0.5 \mathrm{~g}$ of catalyst (40-60 meshes). The feed gas mixture of $90 \% \mathrm{CH}_{4}$ and $10 \% \mathrm{~N}_{2}$ began to be introduced into reactor at $660 \mathrm{ml} / \mathrm{h}$ through a mass flow controller when the temperature reached $973 \mathrm{~K}$ for reaction. An on-line gas chromatograph (GC-17A) equipped with a $6 \mathrm{~m} \times 3 \mathrm{~mm}$ Haye Sep D80/100 column and a CBP1-M50-025 quartz capillary was used to analyse by on-line TCD $\mathrm{N}_{2}, \mathrm{CH}_{4}, \mathrm{CO}, \mathrm{CO}_{2}$ and by on-line FID condensable aromatics such as benzene, toluene and 
naphthalene. The methane conversion and product selectivity without coke were calculated using carbon number.

\section{Results and discussion}

\subsection{XRD studies}

Figure 1 shows the XRD pattern of novel zeolite ITQ-2like. As references, the patterns of MCM-22 precursor, MCM-22 and ITQ-2 are also displayed in figure 1, and their peak positions and relative intensities are in agreement with published literature (Corma et al 1998). The $a$ parameter of MCM-22 (14.27 ̊, calculated by characteristic diffraction peak) is unchanged, which suggests that basic layer structure existing in MCM-22 precursor is retained upon calcination. However, the decrease in the $c$-parameter from $26 \cdot 8$ to $25 \cdot 2 \AA$ indicates that the layers in MCM-22 are closer than those in MCM-22 precursor. Meanwhile, the result also states clearly the supercage of MCM-22 is formed (Lawton et al 1998). The pattern of ITQ-2 also shows a decrease in intensity and a broadening of reflections, which corresponds to its structure of exfoliated layers oriented randomly. ITQ-2-like exhibits a quite similar pattern with ITQ-2, indicating that the basic pore structures of these two samples are consistent (containing 10-ring channels inside the sheet and 12-ring cups penetrating into the sheet from both sides). In addition, we try to calcine ITQ-2-like, and find that the intensity of the diffraction peaks is almost unchanged, which indicates that the texture property of ITQ-2-like is thermally stable.

\subsection{TEM studies}

The TEM pictures of ITQ-2-like, MCM-22 and ITQ-2 are shown in figure 2. As can be seen, ITQ-2-like shows
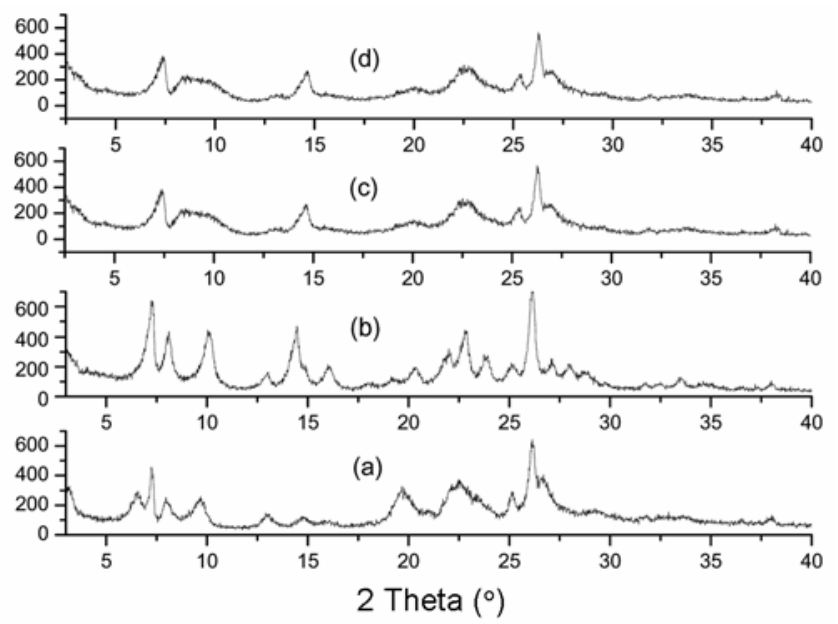

Figure 1. XRD patterns of zeolite: (a) MCM-22(P), (b) MCM-22, (c) ITQ-2-like and (d) ITQ-2. ordered cascaded layers in a face-to-face orientation, which is quite similar to that of MCM-22 (figures 2A and B). Correspondingly, ITQ-2 does not exhibit the typical platelet morphology of MCM-22 precursor crystals, whereas ITQ-2 shows an irregular shape (figure 2C). These results further confirm that ITQ-2-like possesses more ordered layer structure than ITQ-2, as suggested by XRD analysis.

\subsection{TG-DTA and IR studies}

The effectiveness of the detemplation for ITQ-2-like is studied by TG-DTA and IR in figure 3. The DTA profile (figure 3A) of MCM-22 precursor shows two obvious exothermal peaks between 500 and $900 \mathrm{~K}$, which can be assigned to the elimination of the template. However, the DTA profile of ITQ-2-like only displays an obvious endothermal peak at about $350 \mathrm{~K}$ due to physically adsorbed water. The facts imply that the template of ITQ2-like is removed by the treatment with $\mathrm{H}_{2} \mathrm{O}_{2}$. Figure $3 \mathrm{~B}$ shows the IR sectra of ITQ-2-like and MCM-22 precursor. It is well known that the bands at 2935, 2863 and $1469 \mathrm{~cm}^{-1}$ are attributed to $-\mathrm{CH}_{2}-$ groups. The band at $1455 \mathrm{~cm}^{-1}$ corresponds to $-\mathrm{NH}-$ groups. As can be seen from figure $3 \mathrm{~B}, \mathrm{MCM}-22$ precursor contains the template molecules but this is not the case for ITQ-2-like, which indicates that the template of ITQ-2-like is absolutely removed by $\mathrm{H}_{2} \mathrm{O}_{2}$ treatment. The IR results are in agreement with the TG analysis.

\section{$3.4 \quad N_{2}$ adsorption-desorption studies}

Figure 4 presents the $\mathrm{N}_{2}$ adsorption-desorption isotherms of ITQ-2-like, MCM-22 and ITQ-2. The isotherm of MCM-22 corresponds to a type I isotherm, indicating the characteristic of microporosity. And the isotherm of ITQ2-like shows a B-type small hysteresis loop at low relative pressure ( $p / p_{0}$ about $\left.0 \cdot 4\right)$, which is usually related to slit-shaped pores of small size. Different from the isotherms of MCM-22 and ITQ-2-like, the isotherm of ITQ2 zeolite corresponds to a D-type hysteresis loop in IV type isotherm, which is usually attributed to wedgeshaped pores or platelet particles.

According to the adsorption isotherms, the surface area was estimated by $t$-plots method (Johnson 1978), which allowed us to estimate an equivalent microporous volume or mesoporous volume. The textural properties are summarized in table 1 . The microporous surface area of ITQ2-like is $676 \mathrm{~m}^{2} \mathrm{~g}^{-1}$, which is larger than that of MCM-22 and ITQ-2 (624 and $593 \mathrm{~m}^{2} \mathrm{~g}^{-1}$, respectively). Moreover, the external surface area and mesoporous volume of ITQ2-like $\left(43 \mathrm{~m}^{2} \mathrm{~g}^{-1}\right.$ and $\left.0.07 \mathrm{~m}^{3} \mathrm{~g}^{-1}\right)$ are larger than those of MCM-22 $\left(11 \mathrm{~m}^{2} \mathrm{~g}^{-1}, 0.05 \mathrm{~m}^{3} \mathrm{~g}^{-1}\right)$, but less than those of ITQ-2 $\left(187 \mathrm{~m}^{2} \mathrm{~g}^{-1}, 0.23 \mathrm{~m}^{3} \mathrm{~g}^{-1}\right)$. We suppose that the space between thin layers may be exposed after the 


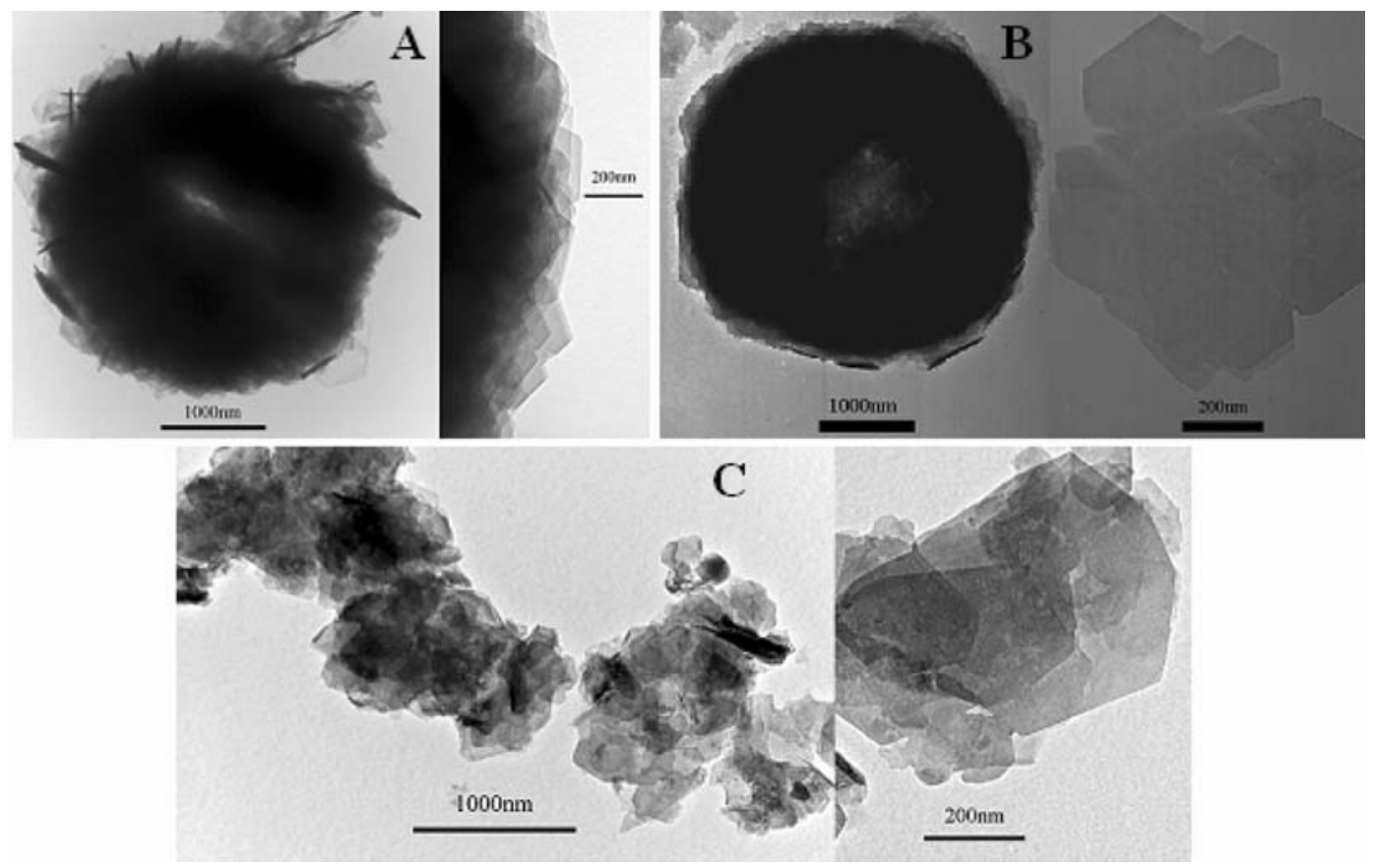

Figure 2. TEM images of MCM-22 (A), ITQ-2-like (B) and ITQ-2 (C).

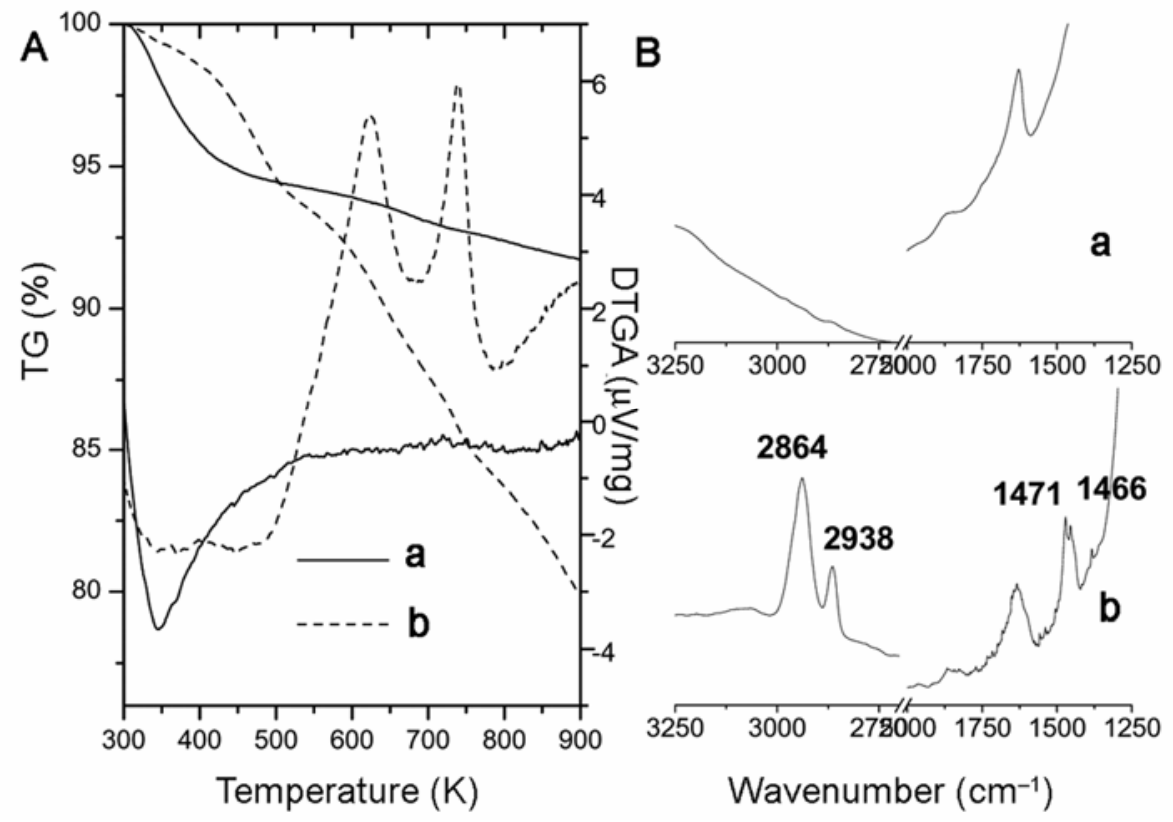

Figure 3. TG-DTA curves (A) and FT-IR spectroscopy (B) of zeolites: (a) ITQ-2like and (b) MCM-22(P).

removal of template via $\mathrm{H}_{2} \mathrm{O}_{2}$ treatment, which leads to the increase of mesopore in ITQ-2-like compared with MCM-22. In the case of ITQ-2, the larger mesoporous volume and external surface area compared with ITQ-2like are attributed to the unrestricted situation of thin layers.

\section{$3.5 d_{3}$-Acetonitrile adsorption studies}

In order to study the catalytic performance of ITQ-2-like, three Mo-containing catalysts are prepared using ITQ-2like, ITQ-2 and MCM-22 as supports. The acidic properties of Mo-supported zeolite Mo is characterized by IR 
spectroscopy of $d_{3}$-acetonitrile adsorption. Figure 5 presents the IR spectra of $d_{3}$-acetonitrile adsorbed on $\mathrm{Mo} / \mathrm{H}$ ITQ-2-like, Mo/H-MCM-22 and Mo/H-ITQ-2. The IR spectra of samples are deconvoluted into two bands at 2323 and $2299 \mathrm{~cm}^{-1}$ which are attributed to the $d_{3^{-}}$ acetonitrile adsorption on strong Lewis acid sites (AlLewis sites) and Brønsted acid sites ( $\mathrm{Si}-\mathrm{OH}-\mathrm{Al}$ groups), and the other two bands at about 2280 and $2265 \mathrm{~cm}^{-1}$ are assigned to the weak coordination of the $\mathrm{C} \equiv \mathrm{N}$ groups to terminal $\mathrm{Si}-\mathrm{OH}$ groups and $\mathrm{C}-\mathrm{D}$ vibrations (Pelmenschikov et al 1993). It is shown that the intensity of Lewis acid (2313-2323 $\left.\mathrm{cm}^{-1}\right)$ and Brønsted acid (2299-2301 $\mathrm{cm}^{-1}$ ) of Mo/H-ITQ-2-like and Mo/H-ITQ-2 are higher than that of Mo/H-MCM-22. In combination with the results of $\mathrm{N}_{2}$ adsorption-desorption isotherm and TEM images of samples, it can be supposed that the higher intensity of Lewis acid and Brønsted acid in ITQ2-like and ITQ-2 may be due to the larger fraction of 12ring cups exposed to the crystal exterior.

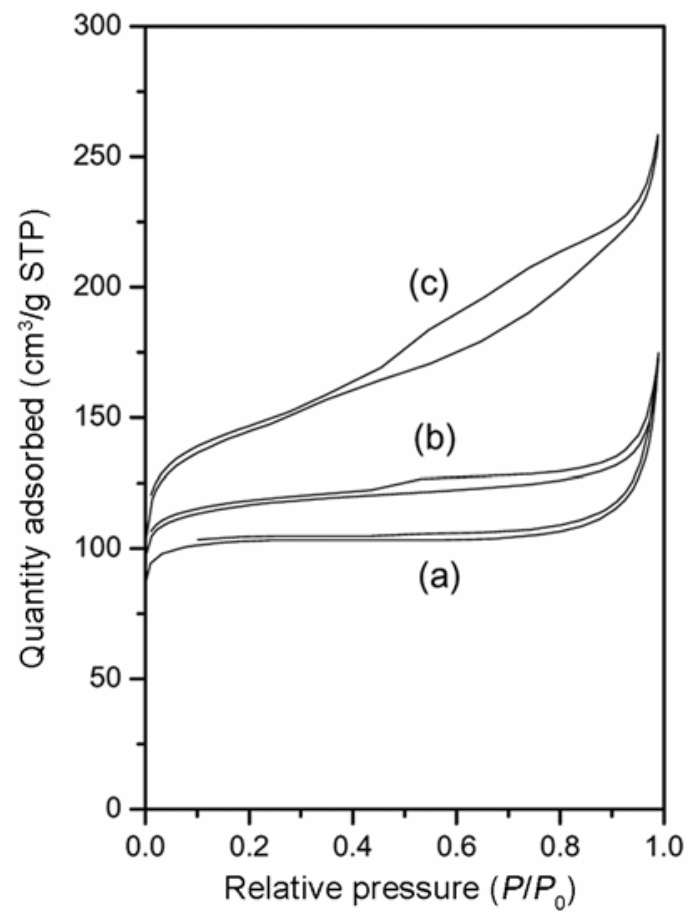

Figure 4. $\mathrm{N}_{2}$ adsorption-desorption isotherms of zeolites: (a) MCM-22, (b) ITQ-2-like and (c) ITQ-2.

Table 1. Numerical values of specific surface area and pore volume of MCM-22, ITQ-2-like and ITQ-2.

\begin{tabular}{lcccc}
\hline Sample & $\begin{array}{c}S_{\text {micro }} \\
\left(\mathrm{m}^{2} \mathrm{~g}^{-1}\right)\end{array}$ & $\begin{array}{c}S_{\text {ext }} \\
\left(\mathrm{m}^{2} \mathrm{~g}^{-1}\right)\end{array}$ & $\begin{array}{c}V_{\text {micro }} \\
\left(\mathrm{cm}^{3} \mathrm{~g}^{-1}\right)\end{array}$ & $\begin{array}{c}V_{\text {meso }} \\
\left(\mathrm{cm}^{3} \mathrm{~g}^{-1}\right)\end{array}$ \\
\hline MCM-22 & 624 & 11 & $0 \cdot 15$ & $0 \cdot 05$ \\
ITQ-2-like & 676 & 43 & $0 \cdot 17$ & $0 \cdot 07$ \\
ITQ-2 & 593 & 187 & $0 \cdot 16$ & $0 \cdot 23$ \\
\hline
\end{tabular}

\subsection{Catalytic results}

The catalytic results of Mo/H-ITQ-2-like, Mo/H-MCM22 and Mo/H-ITQ-2 are displayed in figure 6. It can be seen from figure 6 , that $\mathrm{Mo} / \mathrm{H}-\mathrm{ITQ}$-2-like catalyst reaches its highest activity at about $70 \mathrm{~min}$, which is $5.8 \%$ of methane conversion, higher than Mo/H-MCM-22 (5.3\%). At the same time, Mo/H-ITQ-2-like shows higher selectivity to benzene (68\%) than Mo/H-MCM-22 (58\%). With the increase of reaction time, conversion of methane and the selectivity to benzene over the Mo/H-ITQ-2-like slightly decrease. However, in the whole process of the reaction, Mo/H-ITQ-2-like always exhibits higher methane conversion and benzene selectivity compared with Mo/H-ITQ-2.

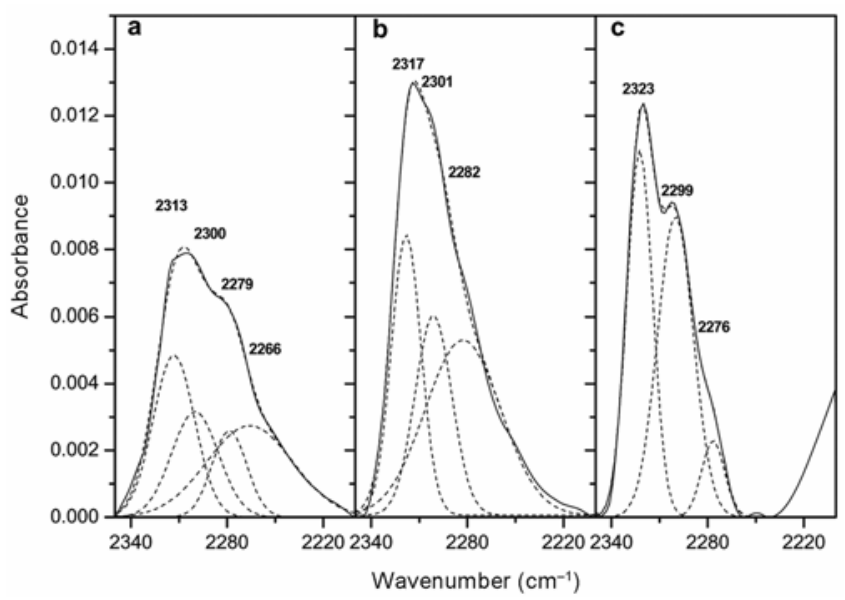

Figure 5. IR spectra of $d_{3}$-acetonitrile adsortion of samples: (a) $\mathrm{Mo} / \mathrm{H}-\mathrm{MCM}-22$, (b) Mo/H-ITQ-2-like and (c) Mo/H-ITQ-2.
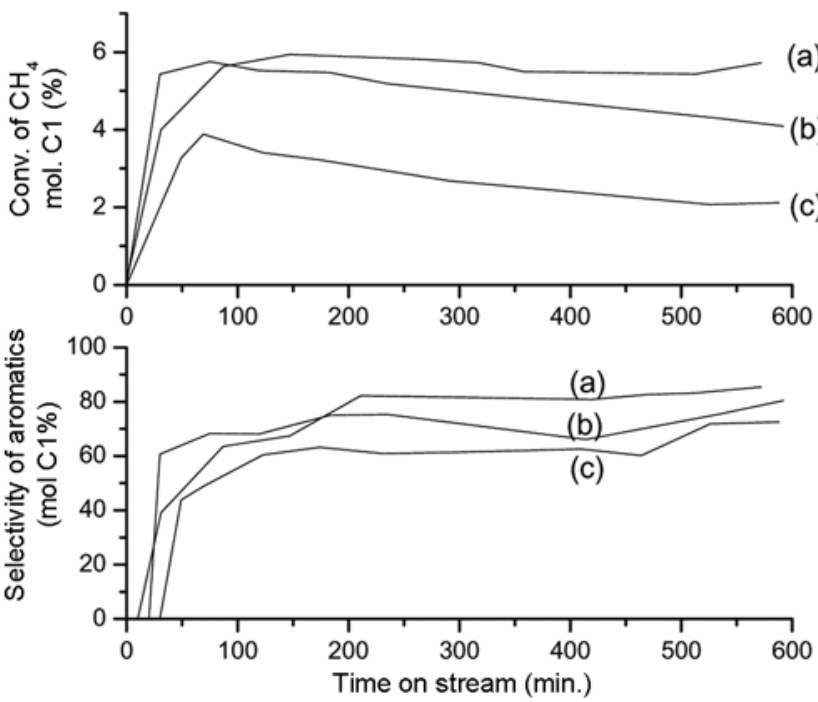

Figure 6. Methane conversion and benzene selectivity without counting for coke over Mo-supported $\mathrm{H}$-form zeolites: (a) Mo/H-MCM-22, (b) Mo/H-ITQ-2-like and (c) Mo/H-ITQ-2. 
The catalyst of Mo/H-MCM-22 exhibits slightly higher stability than Mo/H-ITQ-2-like as the reaction time is extended. Concerning the difference of pore structures between ITQ-2-like and MCM-22, we propose that supercage is beneficial to the activity of aromatization reaction, a conclusion similar to our previous work (Xing et al 2008). However, the increment of special 12-ring cups derived from supercage in Mo/H-ITQ-2-like might be responsible for the decrease of reaction activity. In addition, it can be seen from XRD pattern (figure 1) that the 10-ring channel inside the sheet and 12-ring cups penetrating into the sheet from both sides in zeolite ITQ2-like and ITQ-2 should be quite similar. Therefore, we consider that the higher activity and selectivity to benzene over $\mathrm{Mo} / \mathrm{H}$-ITQ-2-like catalyst might be assigned to the ordered multilayers in comparison with ITQ-2. We suppose that the ordered cascaded layers of ITQ-2-like make shape-selectivity of 12-ring cups kept, whereas the exfoliated and oriented randomly layers of ITQ-2 make shape-selectivity of 12-ring cups decrease due to the lack of spatial constraints.

\section{Conclusions}

New zeolite material ITQ-2-like was successfully prepared by treating MCM-22 precursor using $\mathrm{H}_{2} \mathrm{O}_{2}$. Detemplation of MCM-22 precursor was completed by this approach, and origin topology of MCM-22 precursor was well preserved. Novel zeolite material ITQ-2-like possesses the same pore systems (10-ring channel and 12ring cups) as ITQ-2 zeolite. However, ITQ-2-like due to the ordered multilayers has different nitrogen sorption, acidity and high methane conversion and benzene selectivity in comparison with ITQ-2.

\section{References}

Barth J O, Jentys A, Kornatowski J and Lercher J A 2004 Chem. Mater. 16724

Borry III R W, Kim Y H, Huffsmith A, Reimer J A and Iglesia E 1999 J. Phys. Chem. B103 5787
Čejka J, Krejčī A, Žilková N, Kotrla J, Ernst S and Weber A 2002 Micro. Meso. Mater. 53121

Chen L, Lin L, Xu Z, Li X and Zhang T 1995 J. Catal. 157 190

Corma A, Diaz U, Fornés V, Guil J M, Martínez-Triguero J and Creyghton E J 2000 J. Catal. 191218

Corma A, Fornés V, Pergher S B, Maesen T L M and Buglas J G 1998 Nature 396353

Corma A, Fornés V, Guil J M, Martinez-Triguero J, Creyghton E J and Diaz U 2000 J. Catal. 191218

Corma A, Fornés V, Martínez-Triguero J and Pergher S B 1999 J. Catal. 18657

Ding W, Meitzner G D and Iglesia E 2002 J. Catal. 20614

Harkins W D and Jura G 1943 J. Chem. Phys. 11431

Johnson M F L 1978 J. Catal. 52425

Juttu G G and Lobo R F 2000 Micro. Meso. Mater. 409

Laforge S, Ayrault P, Martin D and Guisnet M 2005 Appl. Catal. A: General 27979

Lawton S L, Leonowicz M E, Partridge R D, Chu P and Rubin M K 1998 Micro. Meso. Mater. 23109

Leonowicz M E, Lawton J A, Lawton S L and Rubin M K 1994 Science 2641910

Ma D, Shu Y, Han X, Xu Y and Bao X 2001 J. Phys. Chem. B105 1786

Melián-Cabrera I, Kapteijn F and Moulijn J A 2005 Chem. Commun. 2178

Pelmenschikov A G, Van S R A, Jänchen J and Meijer E 1993 J. Phys. Chem. 9711071

Rigoreau J, Laforge S, Gnep N S and Guisnet M 2005 J. Catal. 23645

Stephen L L, Anthony S F, Gordon J K, Lawrence B A, Clarence D C, George H H, Daria N L, Mae K R, Hye-Kyung C T, Stefan S and Donald E W 1996 J. Phys. Chem. 1003788

Wang D, Kan Q, Xu N, Wu P and Wu T 2004 Catal. Today 93-95 75

Wang D, Lunsford J H and Rosynek M P 1997 J. Catal. 169 347

Wichterlová B, Tvarůžková Z, Sobalik Z and Sarv P 1998 Micro. Meso. Mater. 24223

Wu P, Kan Q, Wang D, Xing H, Jia M and Wu T 2005 Catal. Commun. 6449

Xing H, Zhang Y, Jia M, Wu S, Wang H, Guan J, Xu L, Wu T and Kan Q 2008 Catal. Commun. 9234

Xu Y, Liu S, Wang L, Xie M and Gou X 1995 Catal. Lett. 30 135 